\title{
Groups in Schutz: \\ The Concrete Meaning Structure of the Socio-Historical World
}

\author{
LESTER EMBREE
}

The most important element in the definition of the private situation is ... the fact that the individual finds himself always a member of numerous social groups (Schutz, Collected Papers II 253).

That fellow-men exist, that men act upon men, ... that social groups ... are integral elements of our life-world, that this life-world has its own history ... are notions that are explicitly or implicitly fundamental for the work of all social scientists (Schutz, Collected Papers I 116).

Certain features ... are common to all social worlds because they are rooted in the human condition. Everywhere we find sex groups and age groups ... and more or less rigid kinship organization ... Everywhere we also find hierarchies of superordination and subordination (Schutz, Collected Papers II 229).

Alfred Schutz (1899-1959) first presented his analysis of the meaning structure of the social world in his aptly titled masterpiece, Der sinnhafte Aufbau der sozialen Welt (1932). This analysis is presented repeatedly during the nearly thirty years of his literary productivity, and it is nicely restated in the late essay, "Symbol, Reality, and Society" (1955), which appears in volume I of Schutz's Collected Papers:

We have ... to indicate that the face-to-face relationship characterized so far is only one, although the most central, dimension of the social world. If we compare it with the world within my actual reach, we can also find dimensions in the social world comparable to the various forms of the world within my potential reach. There is the world of my contemporaries, with whom I am not biographically involved in a face-to-face relationship, but with whom I have in common a sector of time which makes it possible 
for me to act upon them as they may act upon me within a communicative environment of mutual motivation. (In primitive societies in which the souls of the deceased are supposed to participate in the social life of the group, the dead are deemed to be contemporaries.) There is the world of my predecessors, upon whom I cannot act but whose past actions and their outcomes are open to my interpretation and may influence my actions; and there is the world of my successors of whom no experience is possible, but toward whom I may orient my actions in more or less empty anticipation. It is characteristic of all the dimensions of the social world other than the face-to-face relation that I cannot grasp my fellow-men as unique individuals but only experience their typical behavior, their typical pattern of motives and attitudes in thus increasing anonymity. (318)

This set of claims is about the social world in Schutz's broad signification, which, because of the inclusion of predecessors, is better called "the socio-historical world" (an expression he unfortunately does not use), while the expression "social world" in the narrow signification is best reserved for the world exclusively of contemporaries. The latter is the region of the social sciences in the strict signification, whereas the former is the broader region of what are best called the cultural sciences, that, in addition to the strictly social sciences, also subsume the specifically historical sciences, art history and no doubt archaeology, and implicitly the psychological sciences as well.

Although the understanding and/or influencing of individual others by an individual self is crucial for Schutz's analysis of the socio-historical world, there is another scattered and somewhat implicit but more fundamental perspective. Thus, to begin with, he ends "Some Equivocations in the Notion of Responsibility" (1957) with some recognition of relations among groups.

The preceding remarks dealt with the dialectic of the subjective and objective meaning of laws, values, morals, and responsibility merely from the point of view of the individual. But the same dialectic recurs on the level of group relations. Adopting Sumner's classical distinction between in-group and out-group, it can be said that "responsibility," for example, has a different meaning if an in-group and its members acknowledge responsibility for its acts and holds some of its members responsible, or if an out-group makes the in-group and its members responsible for its misdeeds. It is one thing if, in the 
Nuremberg trials, the Nazi leaders were held responsible by the Allied Powers, and quite another thing if they were held answerable by the German people. (Schutz, Collected Papers II 276)

If Schutz is thus willing to speak of groups and group relations, we can wonder if a group of some sort can somehow serve as a collective subject and function like the individual self does in the structure of individuals, and we can also wonder if other groups can then be related to by such a collective subject in ways analogous to how individual consociates, contemporaries, predecessors, and successors are related to by an individual self.

Schutz sometimes seems loath to pursue this possibility, at least in the way in which Edmund Husserl pursued it:

The assumption that communicating subjects constitute personal unities of a higher order, social subjectivities (collectivities) which have as their environment the world of social and cultural objects is entirely unclarified. Does this theory have its root in Hegel or Durkheim or the "organic" school of social sciences (Wundt, for instance) ruling in Germany at the beginning of the century? Or in Rudolf Gierke's legal theory of the "Sozialen Verband" (a term persistently used by Husserl)? The attempts of Simmel, Max Weber, [and] Scheler to reduce social collectivities to the social interaction of individuals is, so it seems, closer to the spirit of phenomenology than the pertinent statements of its founder. (Schutz, Collected Papers III 38; cf. III 80)

It is one thing to assume collectivities or groups without analyzing their components and also personifying or anthropomorphizing them, and it is another thing to proceed — as Schutz doesto consider how individuals within groups understand and influence one another and-for that matter-how groups might do so within larger groups, e.g., African-American and EuropeanAmerican ethnic groups within the USA.

How does Schutz's position include social collectivities or groups? Three points need to be made before an attempt to answer this question. Firstly, while most of Schutz's writing is about individuals, he does discuss groups of contemporaries, groups which he calls "social collectives," which are already found in the Aufbau: 
This large class contains ideal types of quite different degrees of anonymity. The board of directors of a given corporation or the United States Senate are relatively concrete ideal types, and the number of other ideal types which they presuppose is quite limited. But we frequently use sentences in which ideal types like "the state," "the press," "the economy," "the nation," "the people," or perhaps "the working class" ... appear as grammatical subjects. In doing this, we naturally tend to personify these abstractions, treating them as if they were real persons known in indirect social experience. But we are indulging in an anthropomorphism. Actually these ideal types are absolutely anonymous. (Phenomenology of the Social World 198; cf. Collected Papers I 353)

Secondly, "Equality and the Meaning Structure of the Social World" (1955) shows that members of African-American and European-American ethnic groups can share or hold subjective interpretations or meanings in common:

The subjective meaning the group has for its members consists in their knowledge of a common situation, and with it a common system of typifications and relevances. This situation has its history in which the individual members are "at home," that is, they find their bearings without difficulty in the common surroundings, guided by a set of recipes or more or less institutionalized habits, mores, folkways, etc., that help them come to terms with beings and fellow-men belonging to the same situation. The system of typifications and relevances shared with the other members of the group defines the social roles, positions, and statuses of each. (Schutz, Collected Papers II 251)

More will be said about "being at home" below. However, first it is important to add that

social groups have not only subjective but also objective meanings, i.e., they are interpreted from

without by outsiders as well as from within by their insiders. Thus,

The objective meaning of group membership is that which the group has from the point of view of outsiders who speak of its members in terms of "They." In objective interpretation the notion of the group is a conceptual construct of the outsider. By the operation of his system of typifications and relevances he subsumes individuals showing particular characteristics and traits under a social category that is homogeneous merely from his, the outsider's, point of view. (Schutz, Collected Papers II 255)

It is important, moreover, to recognize that Schutz accepts the distinction between existential and voluntary groups from the social science of his time:

I cannot choose my sex or race, nor my place of birth, and, therewith, the national group into which I was born; neither can I choose the mother tongue I learned or the conception of the world taken for granted by the group with which I was indoctrinated during 
childhood. I cannot choose my parents and siblings, or the social and economic status of my parental family. My membership in these groups and the social roles I have to assume within them are existential elements of my situation which I have to take into account, and with which I have to come to terms.

On the other hand, I may choose my spouse, my friends, business partners, my occupation, change my nationality and even my religion. I may voluntarily become a member of existing groups or originate new ones (friendships, marital relations), determine at least to a certain extent the roles I want to assume within them, and even make some efforts to attain by my achievements that kind of position and status within them toward which I aspire. (Collected Papers II 250)

Thus, not only are there groups of at least two kinds with multiple sorts within them and not only are there outsider as well as insider perspectives on them, but the members of groups also share definitions of their common situations. The fact that we can be members of many groups, some of them voluntary, ought not to obscure the truth that we always already are members of groups. This is something not always clear when society is conceived as made up of separate individuals.

Thirdly and finally, while one might think that Schutz considers the individuals concreta out of which various collectiva are assembled, his position is actually that the individual is an abstractum abstracted from intersubjectivity or collective life and, it would follow, the structure of the social world as a structure of individuals rests on an abstraction and is thus abstract, while intersubjectivity is concrete. Thus he writes of a "fictitious abstraction" by which one can consider "the isolated stream of consciousness of a single individual," continuing, "as if the wide-awake man within the natural attitude can be thought of as separated from his fellow-men" (Schutz, Collected Papers I 218, cf. I 167), and also writes repeatedly of "a supposedly isolated individual" (Reflections on the Problem of Relevance 173, cf. 73, I 347). This is also of course how he proceeds in Part II of the Aufbau. Furthermore, he remarks that

we proceeded as if the world were my private world and as if we were entitled to disregard the fact that it is from the outset an intersubjective world ... because we live in 
it as men among other men, bound to them through common influence and work, understanding others and being understood by them. (Schutz, Collected Papers I 10; cf. Collected Papers I 53, 306, Reflections on the Problem of Relevance 134)

The practice of some social scientists to speak of "members" rather than "individuals" thus seems appropriate and Schutz himself mentions membership in a quotation above.

The question of the present essay can now be restated: Does the concrete socio-historical world have a basic structure of groups, perhaps one that is analogous to the structure of abstract individuals that Schutz emphasizes? Such an analogous structure would respect the same differences between the living, the dead, and the unborn and between direct and indirect understanding and/or influencing, but for groups.

An answer to this question can be developed beginning from a passage in a posthumously published manuscript where Schutz unusually begins with contemporaries in not the narrowest signification:

We are concerned exclusively with the world of contemporaries. It consists in a kernel of situations in which the individuals participate in what might be called a face-to-face relationship in the sense that the participants share a sector of space and live together [during] a stretch of time. In other words, each participant knows the other and they act reciprocally one upon the other individual ... This group of consocii is surrounded by various layers of contemporaries characterized by increasing social distance and anonymity ... In many cases the individual is even unable to think of the others who will influence him in terms of individual human beings (management, labor, the Democratic party, etc.). (Schutzian Social Science 270)

At its end this passage refers to others that are collectivities and repeats what was quoted from Aufbau above, whereby there are groups of anonymous contemporaries beyond the region of consociates. But Schutz quickly goes on in this manuscript to indicate that individuals can function within groups: "In the group[s] of consocii (family, congregation, local town hall meeting, local professional group) the individual may talk to individuals, answer questions in immediacy, argue in vivid discussion" (Collected Papers II 250). 
By the passage quoted above, such "groups of consocii" would seem also to include marriages and partnerships and, as shown below, friendships, and thus can have as few as two members. Furthermore and strictly speaking, such groups are made up of consociates only when the members are meeting face-to-face and also, in the groups mentioned, when they meet on a repeating basis.

In "The Homecomer," Schutz accepts from the social sciences of his time to call such repeatedly meeting collectivities "primary groups":

A marriage, a friendship, a family group, [or] a kindergarten, does not consist of a permanent, a strictly continuous, primary face-to-face relationship but rather a series of merely intermittent face-to-face relationships. More precisely, the so-called "primary groups" are institutionalized situations which make it possible to re-establish the interrupted we-relation and to continue where it was broken off last time. (Collected Papers II 111; cf. Phenomenology of the Social World 179 on primary relationships)

"Life at home," alluded to above, is then life in actual or potential primary groups:

It means to have in common with others a section of space and time, and therewith surrounding objects as possible ends and means, and interests based upon [them] as underlying [a] more or less homogeneous system of relevances; it means, furthermore, that the partners in a primary relationship experience one another as unique personalities in a vivid present, by following their unfolding thought as an ongoing occurrence and by sharing, therefore, their anticipations of the future as plans, as hopes or anxieties; it means, finally, that each of them has the chance to re-establish the we-relation, if interrupted, and to continue as if no intermittence had occurred. (Schutz, Collected Papers II 111)

Where might such a primary group be located in a structure of groups analogous to the structure of abstracted individuals emphasized by Schutz from the outset? It may go beyond the letter of Schutz but is still in his spirit to say that, when meeting face-to-face, a group of consociates can be analogous to the I or self in the structure of individuals. One might then speak not in the first person singular but in the first person plural, i.e., of a "We." Such an actualized primary group would then have the collective standpoint from which there can be shared 
meanings or interpretations, self-interpretations included, from which inwardly as well as outwardly directed influence can be exercised.

Next, if the group of consociates that is meeting face-to-face, e.g., a family at the dinner table, is analogous to the individual self, then perhaps other primary groups, e.g., other families met with at a picnic and called "Theys," or better "Thou groups," might be analogous to the individual consociates in the structure of individuals. After all, such other primary groups can have their own collective internal lives of mutual understanding and interaction when members meet, each group has a common situation that it defines and interprets, these common situations then have shared subjective meanings, and such groups are furthermore both in-groups in relation to other groups as out-groups and vice versa, i.e., We-groups and They-groups, “Thougroups" included. Finally, as the examples given show, these primary groups can be of both the existential and the voluntary kinds.

That a group of others thus has its actual or potential collective internal life is not sufficient, however, for it to be, so to speak, in the face-to-face situation as a "Thou-group" (Schutz only speaks of "We-groups" and generally of "They-groups"). It is also necessary that the collective analogs of the individual I and Thou directly share space as well as time and that the primary We-group be thus able to seek directly to understand and influence a primary Thougroup, which modes of direct relating might then be reciprocated. Although perhaps not as frequently for the primary groups that Schutz mentions, this does happen essentially in a football game, where the field and playing time are shared and each team is a We-group against a group of relatively intimate Thous, and this is to say nothing about the large numbers of more anonymous fans in the stands. (The enjoyment of such an actualized mass social relationship of 
mutual orientation and interaction may thus be essential to sports for spectators as well as players.)

If it is amended to refer not only to groups but also to a football jointly focused on by two teams, the following description would then include collective analogs of an I relating to a consociate.

While the face-to-face relationship lasts, we are mutually involved in one another's biographical situation: we are growing old together. We have indeed a common environment and common experiences of the events within it. I and you [or We and a group of Thous], We see the flying bird [or the rolling football]. And the occurrence of the bird's flight [or the ball's roll] as an event in outer (public) time is simultaneous with our perceiving of it, which is an event in our inner (private) time[s]. The two fluxes of inner time, yours and mine [or ours and "thine"], become synchronous with the event in outer time (bird's flight [or ball's roll]) and therewith one with the other. (Schutz, Collected Papers I 317, amended)

Can the analogy of a structure of groups to the structure of individuals be extended further? In the same time but not sharing space there clearly are groups of contemporaries for Schutz, e.g., the Democratic Party, which is formed of more anonymous ideal types than a typical religious group between meeting times at church, temple, or mosque. If such groups of contemporaries can be indirectly understood and influenced by an actualized primary group, e.g., the local town hall meeting in session deciding to support a political party, then the analogy continues to hold.

What of predecessors? In the structure of individuals, a predecessor is ultimately an individual who has died before the self attempts to understand her. For groups, there are indeed always already "dead" groups that can be considered predecessor groups. The problem here concerns how other groups might cease to be. A family, for example, can be considered an existential group that extends indefinitely into the past culturally if not also biologically and, if it 
does not die out, will continue indefinitely into the future. In that signification of "family," one would not speak of predecessor and successor families, but of generations within a family.

Then again, one might think of nuclear families in which a mother, perhaps also a father, and children are a new nuclear family succeeding that in which at least the mother grew up and that new family might itself be succeeded when her children have children of their own. In this signification, there is no need for the "predecessor" groups to die in order to be predecessors (they might best be called "preceding groups"), but they might still be understood to have changed fundamentally when children have their own families, although at least tri-generational families are possible and not unusual when grandparents live long enough. Unilateral and reciprocal understanding and influencing, which could occur face-to-face in multigenerational family gatherings, would differ with the generations involved, grandparents and grandchildren included, but all would be contemporaries and only literally deceased nuclear families would be predecessors.

There are also difficulties for Schutz's voluntary groups, groups formed of other groups included. To be sure, whether simple or compound, these groups can in effect be "born" not only ab ovo, so to speak, when they are founded, but also through mergers or acquisitions of what might then be considered predecessor groups that ceased to exist when the new group was formed and can then be related to by the new group as understandable but not influenceable. Moreover, voluntary groups can also "die" through all of their ultimate individual members literally dying or simply by the group being disbanded. Unborn successor groups can be theorized about analogously. It might seem better simply to say that the socio-historical world contains many groups of various kinds and sorts that are simultaneous or successive with one another and that do or do not directly or indirectly understand and/or influence one another, but it 
is more Schutzian and more phenomenological to consider how a group can most originally be a group, i.e., as a primary group of members meeting face-to-face, how such a We-group can understand and/or influence other groups, "Thou-groups" to begin with, and correlatively have another group or groups in some way or ways understand and/or influence them.

In sum, adjustments being made for how, metaphorically, groups can "live" and "be born" as well as "die," the analogy between the socio-cultural world as a structure of abstract individuals and as a structure of concrete groups holds and can be considered Schutzian in spirit even if beyond his letter. Moreover, while the social world as a structure of individuals emphasized by Schutz is based on an abstraction, one in which a member's group memberships are provisionally set aside, intersubjectivity and the structure of groups is concrete and thus fundamental. It may even be considered to be what ultimately needs to be clarified beginning from the abstract individuals.

\section{Works Cited}

Schutz, Alfred. "The Ethical-Political Side of Schutz: His Contributions at the 1956 Institute on Ethics concerned with Barriers to Equality of Opportunity." Schutzian Social Science. Ed. Lester Embree. Dordrecht: Kluwer Academic Publishers, 1999.

C. Collected Papers, Vol. I. Ed. Maurice Natanson. The Hague: Martinus Nijhoff, 1960.

—. Collected Papers, Vol. II. Ed. Arvid Brodersen. The Hague: Martinus Nijhoff, 1962.

—. Collected Papers, Vol. III. Ed. I. Schutz. The Hague: Martinus Nijhoff, 1966.

- The Phenomenology of the Social World. Translation of Der sinnhafte Aufbau der sozialen Welt (Vienna: Springer, 1932). Trans. George Walsh and Frederick Lehnert. Evanston: Northwestern University Press, 1967.

- Reflections on the Problem of Relevance. Ed. Richard M. Zaner. New Haven and London: Yale University Press, 1970. 